\title{
ANÁLISE MÉTRICA DA COBERTURA FLORESTAL DA BACIA HIDROGRÁFICA DO RIO PEQUENO - PR
}

\author{
METRIC ANALYSIS OF FOREST COVER OF THE WATERSHED PEQUENO RIVER BASIN-PR \\ Franciel Eduardo Rex ${ }^{1}$, Ana Paula Dalla Corte², Verônica Satomi Kazama³ \\ Carlos Roberto Sanquetta ${ }^{4}$ \\ 1,2,3,4 Universidade Federal do Paraná, Curitiba, Paraná, Brasil - francielrexx@gmail.com, \\ anapaulacorte@gmail.com, veronica.kazama@gmail.com \& carlos_sanquetta@hotmail.com
}

\section{RESUMO}

O uso e a ocupação da terra de forma não planejada modificam a paisagem a ponto de torná-la mais suscetível a perturbações ambientais. Dentre as principais perturbações, destaca-se a fragmentação florestal. Para avaliar esse tipo de perturbação o uso do Sistema de Informação Geográfica (SIG) é indicado por apresentar ferramentas de análise espacial apropriadas para esse fim. O objetivo deste estudo é analisar a cobertura florestal da bacia hidrográfica do rio Pequeno com a aplicação de métricas de ecologia de paisagem, assim como analisar a conexão destas áreas com os cursos d'água. Foram utilizados dados vetoriais do uso da terra, hidrografia e da bacia Rio Pequeno, adquiridos pelo Instituto Águas Paraná. A área de estudo apresenta 47,16\% de cobertura florestal, sendo composta pelas classes de vegetação arbórea, vegetação arbustiva e vegetação arbórea plantada. Nessas classes há um elevado número de fragmentos com uma área menor que 10 ha, indicando uma paisagem fragmentada. As classes de vegetação natural apresentam formas mais irregulares $(>2,0)$, enquanto que a classe de vegetação plantada apresenta um padrão mais regular de forma $(1,84)$. Apenas $50 \%$ dos fragmentos de vegetação natural estão conectados aos cursos d'água. Esses resultados indicam que a bacia estudada está sofrendo com perturbações ambientais devido ao uso e ocupação da terra de forma indiscriminada. Portanto, a análise da estrutura e a espacialização via SIG culminam em produção de informações importantes que auxiliam na tomada de decisão para o manejo e conservação da paisagem.

PALAVRAS-CHAVE: Ecologia de Paisagens, Fragmentação florestal, Sistema de informação geográfica

\section{ABSTRACT}

The land use and occupation in an unplanned manner modify the landscape to the point of making it more susceptible to environmental disturbances. Among the main disturbances, we highlight the fragmentation of forests. In order to evaluate this type of disturbance, Geographic Information Systems (GIS) have been indicated, since they have spatial analysis tools that are suitable for this purpose. In this context, the objective of this study is to analyze the forest cover of the watershed Pequeno river basin by using landscape ecology metrics. Besides, the paper intends to analyze the connection of these areas with the water courses. Vectors land use, hydrography and basin limit data were used and acquired by the Águas Paraná Institute. The study area has $47.16 \%$ of forest cover, being composed by the classes arboreal vegetation, shrub vegetation and planted tree vegetation. In these classes there are a high number of fragments, which have an area smaller than 10 ha, indicating a fragmented landscape. Classes of natural vegetation show irregular forms $(>2.0)$, at the same time, the planted vegetation class has a more regular form pattern $(1,84)$. Only $50 \%$ of the fragments of natural vegetation are connected to the waterways. These results indicate that the studied basin is suffering environmental disturbances due to the indiscriminate land occupation. Therefore, the structure and spatialization analysis through GIS has an important role in the production of information, which may help to make decisions in order to manage and conserve the landscape.

KEYWORDS: Landscape ecology, Forest fragmentation, Geographic information system. 


\section{INTRODUÇÃO}

O Bioma Mata Atlântica, que cobria originalmente grande parte do território brasileiro, encontra-se hoje altamente fragmentado, composto por remanescentes muito pequenos, isolados e com baixa diversidade de hábitats (RIBEIRO et al., 2009). De acordo com a último relatório técnico sobre os remanescentes florestais da Mata Atlântica analisada entre o período 2015-2016 pela Fundação sos Mata Atlântica, apontam que o desmatamento nesse bioma aumentou cerca de 57,7\% (SOS MATA ATLÂNTICA, 2017).

O processo de antropização da paisagem brasileira caracterizou-se pela falta de planejamento e consequente supressão dos recursos naturais, principalmente das florestas (RUDOLPHO et al., 2013). A fragmentação florestal representa um dos principais impactos ambientais provenientes da exploração excessiva e desordenada da terra, onde o crescimento de outras áreas tem gerado enormes pressões sobre os ecossistemas florestais, intensificando os processos de fragmentação e perda da diversidade biológica (LIMA \& ROCHA, 2011).

Nesse contexto, pesquisas referentes a fragmentação florestal e seus impactos têm aumentado expressivamente nos últimos anos. Avaliar a estrutura da paisagem é um passo muito importante no diagnóstico de problemas atuais, além disso, serve para prever cenários e apontar mudanças necessárias para manter o equilíbrio natural (CALEGARI et al., 2010).

Por meio de indicadores como tamanho, forma e conectividade entre manchas florestais é possível evidenciar tanto a quantidade de área desflorestada como também a estrutura do ambiente, uma vez que o grau de fragmentação da paisagem indica sua integridade ou qualidade ambiental (IRGANG et al., 2007). Esses indicadores são conhecidos como métricas de ecologia de paisagem, os quais são considerados como base para análises que visam quantificar a estrutura da paisagem. Estes fornecem suporte científico para evidenciar quantidade e qualidade das manchas, considerando principalmente o tamanho do fragmento, a área central, a forma e o grau de seu isolamento (SILVA \& SOUZA, 2014).

Com o aporte de um Sistemas de Informação Geográfica (SIG) e de técnicas do Sensoriamento Remoto (SR) é possível calcular os índices espaciais utilizados em Ecologia da Paisagem, que são capazes de descrever o nível de uniformidade ou fragmentação da paisagem (FERNANDES et al., 2017). Além do mais, esse tipo de análise pode permitir a realização de estudos da paisagem relacionados à biodiversidade, os quais não seriam possíveis de serem realizados somente em campo (SOUZA et al., 2014).

Nesse sentido, objetivo deste estudo é analisar a cobertura florestal da bacia hidrográfica do rio Pequeno, no município de São José dos Pinhas - PR com a aplicação de métricas de ecologia de paisagem e, também, de analisar a conexão destas áreas com os cursos de água.

\section{MATERIAL E MÉTODOS}

\section{Área de estudo}

Compreendida nos limites do município de São José dos Pinhais, no estado do Paraná, a bacia hidrográfica do rio Pequeno está situada entre as coordenadas $(7165000 \mathrm{~N}$ e $682500 \mathrm{E}$ - 7180000N e 705000E), com uma área aproximada de 13044,79 ha.

Em relação a cobertura vegetal, as formações de maior porte predominam nas encostas que limitam a Serra do Mar no alto curso da bacia até o médio curso e são representadas pelas Florestas Ombrófilas Densa Montana e Mista Montana. Entretanto, nas porções mais elevadas com altitude média acima de $1.200 \mathrm{~m} \mathrm{~s}$. n. m., pode ser encontrada a Floresta Ombrófila Densa Altomontana que apresenta associações arbóreas simplificadas e de porte reduzido, regido por condicionantes climáticas e pedológicas mais restritas ao desenvolvimento das árvores (RODERJAN et al., 2002).

\section{Procedimentos metodológicos}

Para a análise métrica e espacial da paisagem foram utilizados dados de uso da terra e da hidrografia da bacia do Alto Iguaçu, em escala 1:20.000 e 1:10.000, respectivamente, disponibilizados pelo Instituto de Águas Paraná. Após aquisição do conjunto de dados, com o uso do Sistema de Informações Geográficas (SIG) ArcGIS 10.4, a bacia do Rio Pequeno foi selecionada, assim como os arquivos referentes ao uso da terra (Figura 1 ) e hidrografia desta área.

O mapa do uso e ocupação da terra da bacia do rio Pequeno (Figura 1), apresenta uma paisagem altamente diversificada, na qual há um predomínio de áreas de Vegetação Arbórea Natural, cerca de $38.66 \%$ em relação à área total da bacia (Tabela 1). 


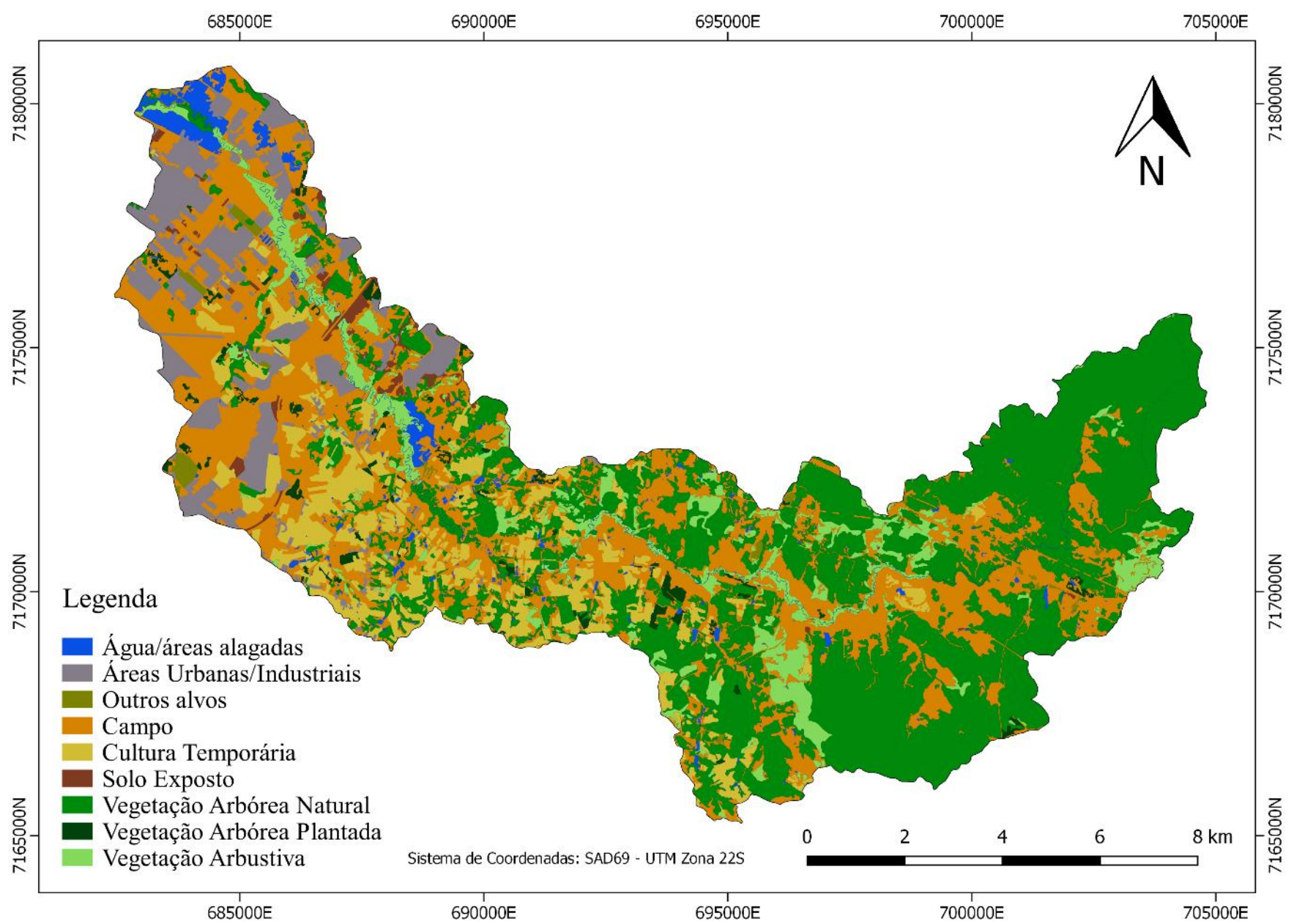

Figura 1: Uso e ocupação da terra da bacia do Rio Pequeno, no município de São José dos Pinhas - PR.

Fonte: SUDERHSA (2000) e ÁGUASPARANA (2017).

Tabela 1. Área em hectares e porcentagem do uso e ocupação da terra da bacia do Rio Pequeno, no município de São José dos Pinhas - PR

\begin{tabular}{ccc}
\hline Classes & Áreas (ha) & Porcentagem (\%) \\
\hline Vegetação Arbórea Natural & $5.043,15$ & 38,66 \\
\hline Campo & $4.157,82$ & 31,87 \\
\hline Culturas Temporárias & $1.253,90$ & 9,61 \\
\hline Áreas Urbanas & 966,84 & 7,41 \\
\hline Veg. Arbustiva & 944,44 & 7,24 \\
\hline Água & 314,82 & 2,41 \\
\hline Veg. Arbórea Plantada & 164,39 & 1,26 \\
\hline Solo Exposto & 110,39 & 0,85 \\
\hline Outros Alvos & 89,04 & 0,69 \\
\hline Total & $\mathbf{1 3 . 0 4 4 , 7 9}$ & $\mathbf{1 0 0}$ \\
\hline
\end{tabular}

Conforme apresenta a Tabela 1, as classes com maior representatividade de área na paisagem da bacia do rio Pequeno são as classes de Vegetação Arbórea Natural e Campo, abrangendo cerca de $38,66 \%$ e $31,87 \%$, respectivamente. Destaca-se que as classes que representam a cobertura florestal da bacia (vegetação arbórea, vegetação arbustiva e vegetação arbórea plantada), apresentam em termos totais uma porcentagem de $47,16 \%$, revelando desta forma um alvo de grande importância para o manejo e conservação destas áreas, principalmente as áreas de cobertura natural, além de que, representam praticamente metade da cobertura do uso da terra da bacia.

Nesse sentido, por apresentarem um valor alto de representatividade, as classes referentes a cobertura florestal foram eleitas para análise métrica e espacial da paisagem e podem ser visualizadas na Figura 2.

Para a obtenção das métricas de Paisagem, foram utilizados os arquivos vetoriais referentes aos fragmentos florestais da bacia do rio Pequeno, ou seja, foram selecionadas as classes de "vegetação arbórea natural", "vegetação arbustiva natural" e "vegetação arbórea plantada". Foi utilizado o software ArcGis 10.4, usando a extensão gratuita V-LATE (Vector-based Landscape Analysis Tools Extension). A partir deste, foram realizados alguns cálculos de índices de ecologia da paisagem referentes à área, borda, forma e área central, conforme ilustra a Tabela 2 . 


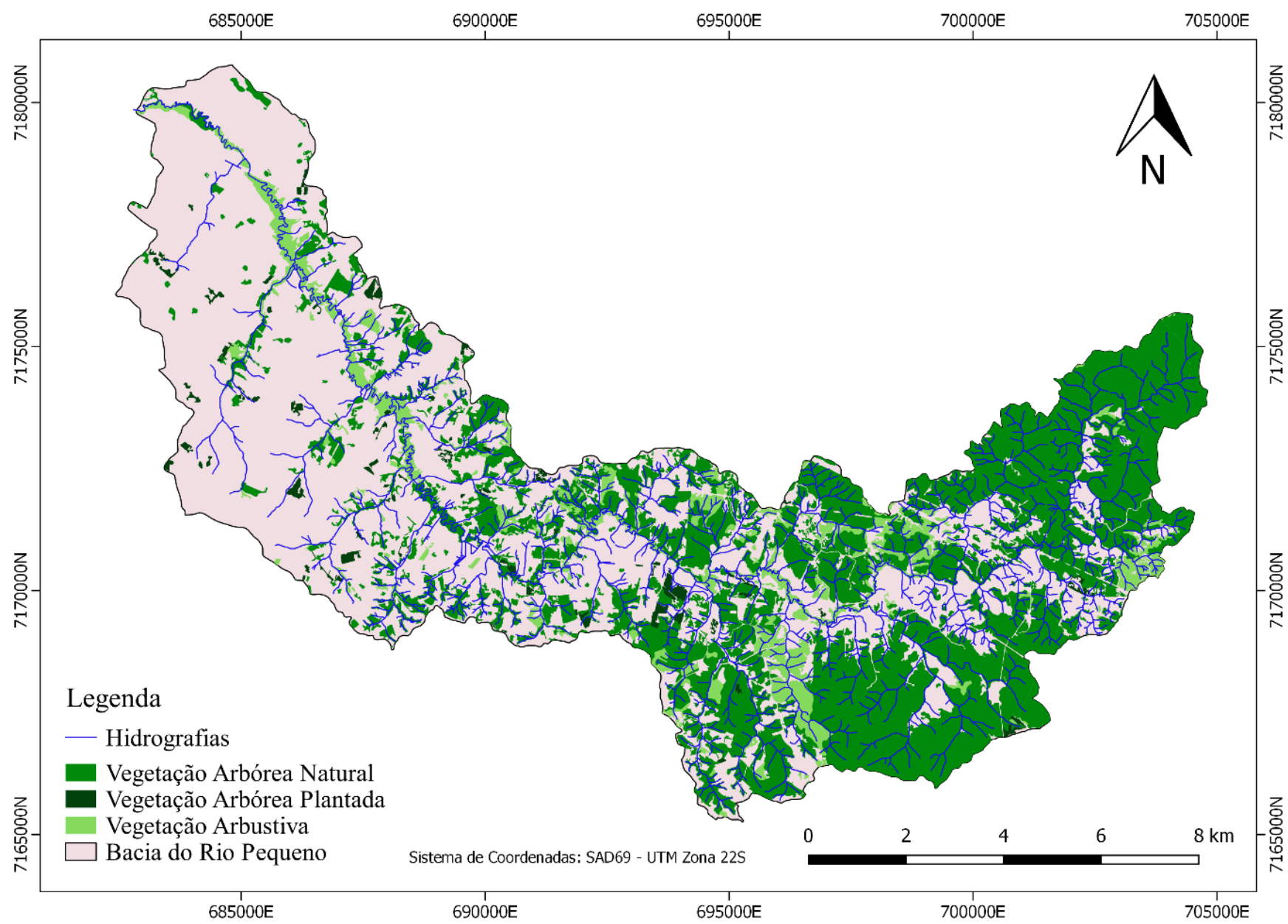

Figura 2: Distribuição das áreas de vegetação florestal na bacia do Rio Pequeno - PR e hidrografias. Fonte: SUDERHSA (2000) e ÁGUASPARANA (2017).

Tabela 2. Métricas de ecologia de paisagem aplicadas nas três classes de vegetação da bacia do Rio Pequeno

\begin{tabular}{|c|c|c|}
\hline Tipo & Métrica & Unidade \\
\hline $\begin{array}{l}\text { Métricas } \\
\text { de área }\end{array}$ & $\begin{array}{c}\text { Área Total } \\
\text { Número de Fragmentos }\end{array}$ & $\begin{array}{l}\text { ha } \\
\text { - }\end{array}$ \\
\hline $\begin{array}{l}\text { Métricas } \\
\text { de borda }\end{array}$ & $\begin{array}{c}\text { Densidade das bordas } \\
\text { Total de bordas }\end{array}$ & $\begin{array}{c}\mathrm{m} / \mathrm{ha} \\
\mathrm{m}\end{array}$ \\
\hline $\begin{array}{l}\text { Métrica } \\
\text { de forma }\end{array}$ & $\begin{array}{l}\text { Índice médio de forma } \\
\text { Razão Média Perímetro-Área }\end{array}$ & - \\
\hline Área central & $\begin{array}{c}\text { Área Central Total } \\
\text { Índice De Área Central }\end{array}$ & $\begin{array}{l}\text { ha } \\
\%\end{array}$ \\
\hline
\end{tabular}

Para os cálculos das métricas de área central utilizou-se o valor de $100 \mathrm{~m}$ de distância. Este valor foi escolhido devido ao maior desempenho computacional apresentado, conforme visto por Lucas (2011), e também pelo fato de que valores acima de $100 \mathrm{~m}$ levam a uma redução significativa nos valores das métricas de área central dos fragmentos médios passando a uma porcentagem de área central insignificante (PIROVANI, 2010). Foi realizado uma análise de conectividade através de seleção por localização entre as classes de cobertura florestal com a hidrografia da área de estudo. Para tal, foram definidas 4 classes de conectividade, que levaram em consideração a distância, e são descritas a seguir:

- 1a Classe: Distância de zero metros, ou seja, conectividade direta entre os fragmentos com a rede hidrográfica;

- 2a Classe: Distância de até 100 m;

- 3a Classe: Distância de até $200 \mathrm{~m}$; e

- 4ạ Classe: Distância de até $400 \mathrm{~m}$.

\section{RESULTADOS E DISCUSSÃO}

\section{Análise das métricas de ecologia da paisagem}

Em relação as métricas de ecologia da paisagem da área de estudo, na Tabela 3 é apresentado o resultado encontrado. 
Tabela 3. Métricas de ecologia de paisagem aplicadas nas três classes de fragmentos florestais da bacia do Rio Pequeno - PR

\begin{tabular}{|c|c|c|c|c|}
\hline \multirow[b]{2}{*}{ Grupo } & \multirow[b]{2}{*}{ Métrica } & \multicolumn{3}{|c|}{ Fragmentos florestais } \\
\hline & & $\begin{array}{c}\text { Arbórea } \\
\text { natural }\end{array}$ & $\begin{array}{c}\text { Arbustiva } \\
\text { natural }\end{array}$ & Plantada \\
\hline \multirow{2}{*}{1} & Área total (ha) & $5.043,15$ & 944,44 & 164,13 \\
\hline & № de fragmentos & 418 & 268 & 85 \\
\hline \multirow{2}{*}{2} & $\begin{array}{l}\text { Densidade de } \\
\text { borda ( } \mathrm{m} / \mathrm{ha} \text { ) }\end{array}$ & 148,32 & 344,17 & 436,87 \\
\hline & $\begin{array}{l}\text { Total de borda } \\
\qquad(\mathrm{km})\end{array}$ & 748,01 & 325,04 & 71,70 \\
\hline \multirow{2}{*}{3} & $\begin{array}{c}\text { Índice médio } \\
\text { de forma }\end{array}$ & 2,11 & 2,19 & 1,84 \\
\hline & $\begin{array}{l}\text { Razão média } \\
\text { perímetro-área }\end{array}$ & 0,819 & 0,57 & 0,08 \\
\hline \multirow{2}{*}{4} & $\begin{array}{l}\text { Área central } \\
\text { total (ha) }\end{array}$ & $1.748,36$ & 31,47 & 0,18 \\
\hline & $\begin{array}{c}\text { Índice de área } \\
\text { central (\%) }\end{array}$ & 34,67 & 3,33 & 0,11 \\
\hline
\end{tabular}

A bacia do Rio Pequeno possui uma área total de 13.044,79 ha, dos quais foram mensurados 418 fragmentos florestais de vegetação arbórea natural, esses fragmentos apresentaram um total de 5.043,15 ha, sendo responsável por $38,66 \%$ da proporção da paisagem. A vegetação arbustiva apresentou um total de 268 fragmentos na paisagem, que totalizaram em termos de área 944,44 ha, e a vegetação arbórea plantada, apresentou o menor número de fragmentos, foram computados 85 fragmentos que apresentaram um total de 164,13 ha.

Na Figura 3 é apresentada a distribuição do número de fragmentos por classes de tamanho.

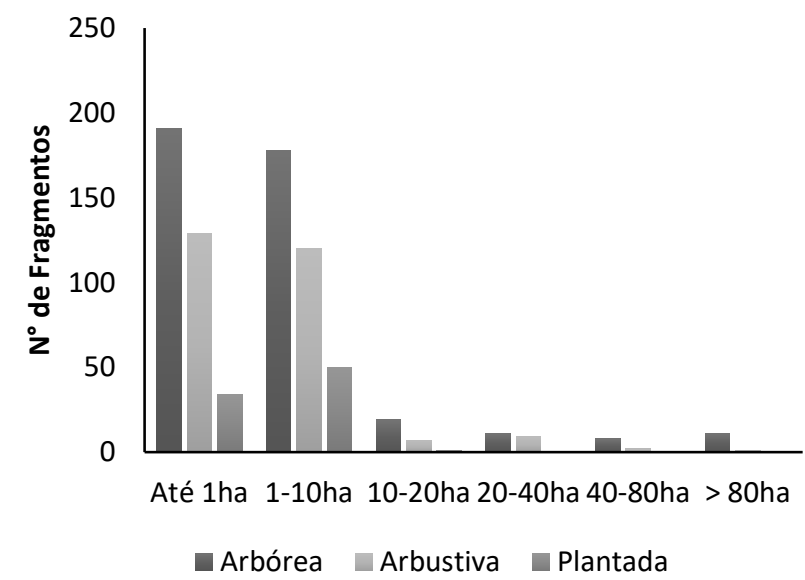

Figura 3. Número de Fragmentos por classes de tamanho de área para os três tipos de fragmentos florestais da bacia do Rio Pequeno - PR.

De modo geral, os fragmentos de todas as classes apresentam uma maior quantidade de pequenos fragmentos. Garcia (2011) relata que a fragmentação de uma paisagem pode ocasionar vários impactos, sobretudo porque a fragmentação ocasiona problemas para o microclima especialmente nas bordas das matas onde um aquecimento maior é gerado por estarem mais expostas a incidência de luz. A fragmentação atinge diretamente o desenvolvimento de populações naturais, podendo gerar diversas consequências negativas para os ecossistemas, como a redução da biodiversidade e de variabilidade genética, por exemplo (GARCIA, 2011).

A classe de vegetação arbórea natural, que apresenta em larga escala uma grande quantidade de fragmentos com até 10 ha. Esses resultados somam-se com um estudo recente conduzido por Santos et al. (2017) no qual, os autores encontraram superioridade numérica dos fragmentos pequenos. Além do mais, pode-se citar outros estudos que apresentam similar situação em um número superior de fragmentos pequenos do domínio Mata Atlântica (SILVA, 2002; RIBEIRO et al., 2009; CALEGARI et al., 2010; JUVANHOL et al., 2011; PIROVANI et al., 2014).

A classe de vegetação arbustiva também apresenta em sua maioria pequenos fragmentos, para essa classe existem poucos fragmentos maiores que $40 \mathrm{ha}$. A classe de vegetação arbórea plantada não apresenta fragmentos com áreas superiores a 20 ha.

Com a análise gráfica pode-se inferir que esses resultados são um indicativo do quanto a bacia em questão se apresenta fragmentada, uma vez que, cerca de $90 \%$ dos fragmentos de vegetação arbórea e arbustiva natural apresentam áreas menores que 10 ha. Para Mcgarigal \& Marks (1995) as paisagens que apresentam menores valores para área de fragmento devem ser consideradas como as mais fragmentadas. São por estes e outros resultados, que a Mata Atlântica é considerada um hotspot mundial, ou seja, uma das áreas mais ricas em biodiversidade e, ao mesmo tempo, mais ameaçadas do planeta (MYERS et al., 2000).

Em relação as métricas, para o parâmetro borda, duas métricas foram calculadas. A métrica de densidade de borda, apresentou o maior valor para a classe de vegetação plantada, sendo o valor encontrado de $436,87 \mathrm{~m} / \mathrm{ha}$, esse resultado refere-se ao menor número de fragmentos bem como o tamanho inferior dos fragmentos, para essa classe não foram observados fragmentos com áreas superiores a 20ha.

A classe de vegetação arbustiva apresentou um valor um pouco abaixo $(344,17 \mathrm{~m} / \mathrm{ha})$ e a classe vegetação arbórea natural apresentou o menor valor de densidade de borda $(148,32 \mathrm{~m} / \mathrm{ha})$. Os valores densidade de borda 
indicam que quanto maior o índice de densidade de borda, consequentemente haverá elevada fragmentação da paisagem (MCGARIGAL et al., 2012). Nesse sentido, os fragmentos de vegetação arbórea natural apresentam-se melhores conservados por possuírem menor densidade de borda, portanto, estão menos sujeitos aos chamados efeitos de borda.

Esse resultado pode ter sido encontrado devido ao fato de que para a classe de fragmentos de vegetação arbórea natural há fragmentos com áreas superiores a 1.000 ha, nesse sentido, por se tratar de uma média da classe foi encontrado um valor de índice de densidade de borda menor que as demais classes.

Já para o total de borda, as ordens são invertidas, o maior valor é encontrado para a vegetação arbórea natural, seguida da arbustiva e o menor valor para a classe de vegetação plantada, a média de borda por fragmento segue esse mesmo padrão e os valores foram expostos anteriormente na Tabela 3. Esse resultado também era esperado, uma vez que na área existem muitos mais fragmentos de vegetação arbórea natural com tamanhos superiores que as demais classes.

De acordo com Murcia (1995) citado por Dantas et al. (2017) as características de borda podem afetar os organismos do fragmento, fazendo com que alguns organismos evitem o ambiente de borda tendo em vista a mudança brusca nas condições bióticas e abióticas. Entre estas alterações estão os efeitos sobre o microclima, como o aumento da temperatura, luminosidade e redução da umidade, além de ruídos e uma maior exposição aos ventos aos quais as espécies de interior não estão adaptadas. No entanto, algumas espécies podem se beneficiar dessas condições de borda e aumentar sua densidade, tornando-se um elemento de perturbação para a estrutura da comunidade em uma mancha remanescente.

As métricas de forma objetivam comparar a razão perímetro/área com a forma padrão, indicando a regularidade da forma (PIROVANI, 2010), em outras palavras, estas métricas indicam o quanto o fragmento está vulnerável a influências externas, estando relacionadas à intensidade do efeito de borda (LIMA \& ROCHA, 2011).

Foi observada maior irregularidade para as classes vegetação arbórea natural $(2,11)$ e arbustiva $(2,19)$, sendo a classe de vegetação plantada mais regular $(1,84)$. Os índices de forma são indicadores da configuração da paisagem. Assim, valores próximos ou igual à 1 refere-se a formas mais regulares, ou, quando todos os fragmentos forem circulares. À medida que a irregularidade da forma (fragmento) cresce, o valor do índice aumenta (MCGARIGAL \& MARKS, 1995).

$O$ índice de forma médio também foi verificado por Lucas (2011), que encontrou de modo geral, valores irregulares para fragmentos da classe Floresta Estacional Semidecidual $(2,10)$, sendo que para a classe de Reflorestamento o índice encontrado pelo autor apresentou um padrão mais regular de forma $(2,02)$. Estes resultados corroboram com o exposto neste trabalho e demonstram que modo geral que, fragmentos de vegetação natural geralmente apresentam uma forma mais irregular, enquanto que, em povoamentos florestais, ou seja, em área de vegetação plantada apresentam um padrão mais regular de forma, devido aos tratos culturais que são empregados na atividade de plantio.

Ainda em concordância com os resultados encontrados neste estudo, Santos et al. (2017) comentam que fragmentos florestais com áreas menores apresentaram formato mais regular quando comparados com os fragmentos médios, grandes e muito grandes. E que os fragmentos de maior área possuem a desvantagem de a irregularidade da forma ser acentuada.

A média da razão perímetro-área (MPAR) apresentou os maiores valores para as classes de vegetação natural, sendo encontrado o valor de 0,81 para a classe Arbórea e de 0,57 para a classe Arbustiva, e um baixo valor para a classe de vegetação Plantada $(0,08)$. Esses valores já eram esperados, visto que quanto mais próximo de 1 for o valor do índice de forma médio do fragmento, menor será sua razão perímetro/área (BORGES et al., 2004). Ademais, estes resultados concordam com os encontrados por Santos et al. (2017). Os autores explicam que mesmo apresentando formatos mais irregulares, os fragmentos maiores estão sob menor efeito de borda, visto que apresentam uma MPAR menor, isto é, a proporção de área é superior à de borda.

O último parâmetro avaliado referente as métricas deste trabalho foi a área central, sendo que, para a área central total da vegetação arbórea natural foi encontrado um valor de 1748,46 ha, o qual entre as classes de cobertura florestal foi o maior valor, seguida da classe arbustiva (31,47 ha) e da classe de vegetação plantada, com um baixo valor $(0,18 \mathrm{ha})$.

Os índices de área central encontrados para as classes foram de $34,67 \%, 3,33 \%$ e de $0,11 \%$ para as classes arbórea natural, arbustiva e plantada, respectivamente. Para esse índice percebe-se que a classe de vegetação arbórea natural apresenta a menor intensidade dos efeitos adversos encontrados na margem do fragmento, ou seja, do total de área desta classe, cerca de $34,67 \%$ das áreas 
sofrem com menos intensidades. Para as demais classes, observa-se que os fragmentos destas áreas sofrem mais, uma vez que foram observados índices de área central relativamente baixos.

Do ponto de vista conservacionista, a estrutura da vegetação arbórea natural sugere que, por apresentar maiores valores de área central acima de 10ha, tem maior possibilidade de oferecer áreas mínimas para a sobrevivência das populações (METGZER, 1999 citado por PIROVANI, 2010), o que não pode ser inferido para as demais classes, uma vez que foram encontrados índices baixos de área central e poucos fragmentos com áreas superiores a 10 ha.

\section{Análise da conectividade dos fragmentos}

Para a análise da conectividade dos fragmentos, foi levada em consideração a hidrografia que foi apresentada na Figura 2, que ilustra as classes de vegetação já avaliadas anteriormente pelas métricas de ecologia de paisagem sobrepostas pela hidrografia da bacia do rio Pequeno. 0 resultado da análise de conectividade dos fragmentos é exposto na Tabela 4.

Tabela 4. Número de fragmentos e área em hectares provindos da seleção por localização da conectividade de fragmentos com a hidrografia

\begin{tabular}{ccccccc}
\hline \multirow{2}{*}{ Classes } & \multicolumn{2}{c}{ Plantada } & \multicolumn{2}{c}{ Arbustiva } & \multicolumn{2}{c}{ Arbórea } \\
\cline { 2 - 7 } & $\mathrm{N}$ & ha & $\mathrm{N}$ & ha & $\mathrm{N}$ & ha \\
\hline $0 \mathrm{~m}$ & 21 & 63,3 & 134 & 835,1 & 205 & 4851,4 \\
$100 \mathrm{~m}$ & 59 & 118,7 & 256 & 931,2 & 358 & 4978,5 \\
$200 \mathrm{~m}$ & 75 & 150,7 & 263 & 941,7 & 386 & 5002,4 \\
$400 \mathrm{~m}$ & 80 & 157,4 & $\mathbf{2 6 8}$ & 944,4 & 402 & 5017,2 \\
\hline Total & $\mathbf{8 5}$ & $\mathbf{1 6 4 , 1}$ & $\mathbf{2 6 8}$ & $\mathbf{9 4 4 , 4}$ & $\mathbf{4 1 8}$ & $\mathbf{5 0 4 3 , 1}$ \\
\hline
\end{tabular}

$\mathrm{Na}$ Tabela 4, são expostos os resultados da conectividade dos fragmentos por classes de distâncias. a primeira classe ( 0 metros) não levou em consideração nenhuma distância, ou seja, o resultado dessa seleção refere-se realmente a conectividade dos fragmentos com os cursos de água (hidrografia), para tal, tem-se como resultado de 21 fragmentos conectados de vegetação plantada, 134 fragmentos de vegetação arbustiva e 205 fragmentos para a vegetação arbórea.

Percebe-se que em termos de porcentagem de fragmentos conectados, as classes de vegetação arbustiva e arbórea natural apresentam cerca de $50 \%$ de fragmentos conectados aos cursos de água, e a classe vegetação plantada um valor próximo de $25 \%$. A menor porcentagem de conexão da classe vegetação plantada, refere-se aos tratos silviculturais empregados para esse tipo de vegetação. Geralmente, plantios florestais não são alocados em áreas próximas a hidrografias.

Assim, dando ênfase aos fragmentos de origem arbórea natural e arbustiva, percebe-se que estes ocorrem de forma fragmentada na paisagem, ou seja, apresentam-se espalhados e desconexos, provavelmente pelo processo de antropização dos recursos naturais que se caracteriza pela falta de planejamento e consequente destruição desses. Segundo Tabarelli et al. (2004) a expansão da fronteira agrícola torna os remanescentes de vegetação nativa dispersos em áreas privadas, que vão aos poucos se convertendo em áreas antropizadas. Essa observação pode ser visualizada a partir do mapa do uso e ocupação da terra da bacia, em que, é possível observar pequenos fragmentos entre áreas de cultura temporária e áreas de campo (Figura 1).

Com o aumento das distâncias percebe-se um aumento dos fragmentos, destacando principalmente as classes de vegetação arbustiva, que à 100 metros de distância apresenta uma porcentagem média de $95 \%$ de conexão, e a classe arbórea natural que apresenta $85 \%$ de conexão dos fragmentos com os cursos de água. Desta forma, podese inferir que, apesar dos fragmentos não estarem conectados aos rios, percebe-se que há uma proximidade entre esses até $100 \mathrm{~m}$ de distância. Com até $400 \mathrm{~m}$ todos os fragmentos de vegetação arbustiva estão conectados aos cursos de água.

Nesse sentido, entende-se que se houvesse o cumprimento das leis que tange o código florestal sob as áreas de preservação permanente, além de uma provável ligação entre os fragmentos, haveria também o aumento de áreas de vegetação natural. Os fragmentos florestais, uma vez conectados às APP, integram-se ao sistema de corredores ecológicos. De acordo com Spellerberg \& Sawyer (1999) a união dos fragmentos traz como consequência, além do aumento da área florestada, a reconstituição da mata ciliar e a redução do grau de fragmentação. Com a realização do presente estudo ações podem ser incentivadas para futuras adequações dessas áreas, tais como o estabelecimento de corredores ecológicos como uma alternativa para a recomposição da paisagem do rio Pequeno.

\section{CONCLUSÕES}

Por meio das análises realizadas foi possível observar que a cobertura florestal da bacia do rio Pequeno está fortemente fragmentada, uma vez que apresenta muitos fragmentos com valores de área inferiores a $10 \mathrm{ha}$. 
As métricas de ecologia de paisagem permitiram observar a condição das classes de cobertura florestal. Dentre as métricas, percebe-se que os fragmentos de vegetação arbórea natural são os que apresentaram formas mais irregulares em relação as outras classes. Em contrapartida, estão sob menor efeito de borda, visto que apresentam a proporção de área superior à de borda.

A análise de conectividade dos cursos de água com os remanescentes florestais revelou-se como uma ferramenta muito importante para o manejo de áreas naturais. Apenas $50 \%$ dos fragmentos de vegetação arbórea natural estão conectados à hidrografia. Por outro lado, quando distantes em 100 metros 90\% deles apresentam conexões com os cursos d'água.

\section{AGRADECIMENTOS}

Agradecimentos ao Instituto Águas Paraná, por ceder os dados vetoriais utilizados neste trabalho referentes a bacia hidrográfica do Alto Iguaçu - PR; e ao CNPq e a CAPES pelas bolsas de estudos.

\section{REFERÊNCIAS}

AGUASPARANÁ - INSTITUTO DAS ÁGUAS DO PARANÁ. Uso do solo - Bacia do Alto Iguaçu. 2017. Disponível em: http://www.aguasparana.pr.gov.br/modules/conteudo/conteud o.php?conteudo $=92$

BORGES, L.F.R. et al. Inventário de fragmentos florestais nativos e propostas para seu manejo e o da paisagem. Revista Cerne, v.10, n.1, p.22-38, 2004.

CALEGARI, L. et al. Análise da dinâmica de fragmentos florestais no município de Carandaí, MG, para fins de restauração florestal. Revista Árvore, v.34, n.5, p.871-880, 2010.

DANTAS, M.S. et al. Diagnóstico da vegetação remanescente de Mata Atlântica e ecossistemas associados em espaços urbanos. Journal of Environmental Analysis and Progress, v.2, p.87-97, 2017.

FERNANDES, M. et al. Ecologia da Paisagem de uma Bacia Hidrográfica dos Tabuleiros Costeiros do Brasil. Floresta e Ambiente, v.24, e00025015, 2017.

GARCIA, D. Efectos biológicos de la fragmentación de hábitats: nuevas aproximaciones para resolver un viejo problema. Ecosistemas, v.20, n.2, p.1-10, 2011.

GARCIA, L.S. et al. Fragmentação florestal e sua influência sobre a fauna: estudo de caso na Província Ocidental da Amazônia, município de Urupá, estado de Rondônia. 160 Simpósio Brasileiro de Sensoriamento Remoto, p.3163-3170, 2013.

IRGANG, G.V. et al. Análise da fragmentação da paisagem e mapeamento do valor para a conservação. Cuiabá: ICV, 2007.
JUVANHOL, R.S. et al. Análise Espacial de Fragmentos Florestais: Caso dos Parques Estaduais de Forno Grande e Pedra Azul, Estado do Espírito Santo. Floresta e Ambiente, v.18, n.4, p.353-364, 2011.

LIMA, R.N.S.; ROCHA, C.H.B. Técnicas de sensoriamento remoto e métricas de ecologia da paisagem aplicadas na análise da fragmentação florestal no município de Juiz de Fora - MG em 1987 e 2008. 15 Simpósio Brasileiro de Sensoriamento Remoto - SBSR, p.2067-2074, 2011.

LUCAS, D.F. Análise Espacial dos Fragmentos Florestais no Município de São Gonçalo do Rio Abaixo/MG. 2011. 45p. (Monografia de especialização).

MCGARIGAL, K. et al. FRAGSTATS v4: spatial pattern analysis program for categorical and continuous maps. 2012. Disponível em: http://www.umass.edu/landeco/research/fragstats/fragstat s.html

MCGARIGAL, K.; MARKS, B.J. Fragstats: Spatial pattern analysis program for quantifying landscape structure. Portland: General Technical Report, 1995.

MURCIA, C. Edge effects in fragmented forests: implications for conservation. Tree, v.2, p.58-62, 1995.

MYERS, N. et al. Biodiversity hotspots for conservation priorities. Nature, v.403, n.67772, p.853-845, 2000.

PIROVANI, D.B. Fragmentação, florestal, dinâmica e ecologia da paisagem na bacia hidrográfica do rio Itapemirim, ES. 2010. 106p. (Dissertação de mestrado).

PIROVANI, DB. et al. Spatial analysis of forest fragments in the Itapemirim River Basin, ES. Revista Árvore, v.38, n.2, p.271-281. 2014.

RIBEIRO, M.C. et al. The Brazilian Atlantic Forest: How much is left, and how is the remaining forest distributed? Implications for conservation. Biological conservation, v.142, n.6, p.1141-1153, 2009.

RODERJAN, C.V. et al. As unidades fitogeográficas do estado do Paraná. Ciência \& Ambiente, n.24, p.75-92, 2002.

RUDOLPHO, L.S. et al. Aplicação de técnicas de geoprocessamento e métricas da paisagem na análise temporal da cobertura florestal da Bacia do Ribeirão Fortaleza em Blumenau/SC. 160 Simpósio Brasileiro De Sensoriamento Remoto, p.1742-1749, 2013.

SANTOS, J.F.C. et al. Fragmentação florestal na Mata Atlântica: o caso do município de Paraíba do Sul, RJ, Brasil. Revista Brasileira de Biociências, v.15, n.3, p.151-158, 2017.

SILVA M.S.F.; SOUZA, R.M. Spatial patterns of forest fragmentation in the Flona Ibura - Sergipe. Mercator, v.13, n.3, p.121-137, 2014.

SILVA, V.V. Médio Vale do Paraíba do Sul: Fragmentação e Vulnerabilidade dos Remanescentes de Mata Atlântica. 2002, 123p. (Dissertação de mestrado). 
SOS MATA ATLÂNTICA. Atlas dos remanescentes florestais da Mata Atlântica: Período 2015-2016, 2017. Disponível em: https://www.sosma.org.br/link/Atlas_Mata_Atlantica_2015-201 6_relatorio_tecnico_2017.pdf

SOUZA G.C. et al. Análise da fragmentação florestal da Área de Proteção Ambiental Coqueiral, Coqueiral - MG. Ciência Florestal, v.24, n.3, p.631-644. 2014

SPELLEBERG I.F.; SAWYER, J.W.D. An introduction to applied biogeography. Cambridge: Cambridge University Press, 1999.

SUDERHSA - Superintendência de Desenvolvimento de Recursos Hídricos e Saneamento Ambiental do Paraná. Uso do solo - Bacia do Alto Iguaçu. Escala 1:20.000. Curitiba, 2000. Disponível em: http://www.aguasparana.pr.gov.br/modules/conteudo/conteud o.php?conteudo=92.

TABARELLI, $M$. et al. Forest fragmentation, synergisms and the impoverishment of Neotropical forests. Biodiversity and Conservation, v.13, n.7, p.1419-1425, 2004. 